\title{
Lexico-Semantic Ways in Medical Terms Formation through Logical Tasks and Exercises When Teaching Kyrgyz Speaking Groups
}

\author{
Altynai Satyvaldieva1, Bibira Bekboeva², Flura Batyrshina1, Zhypargul Abdullaeva ${ }^{3 *}(\mathbb{C}$ \\ ${ }^{1}$ Department of World Languages and Cultures, Osh State University, Osh, Kyrgyzstan \\ ${ }^{2}$ Educational Scientific Production Complex, International University of Kyrgyzstan, Bishkek, Kyrgyzstan \\ ${ }^{3}$ Science and Research Department, Osh State University, Osh, Kyrgyzstan \\ Email: *jypar.science@oshsu.kg
}

How to cite this paper: Satyvaldieva, A., Bekboeva, B., Batyrshina, F., \& Abdullaeva, Z. (2021). Lexico-Semantic Ways in Medical Terms Formation through Logical Tasks and Exercises When Teaching Kyrgyz Speaking Groups. Open Journal of Modern Linguistics, 11, 640-646.

https://doi.org/10.4236/ojml.2021.114049

Received: July 20, 2021

Accepted: August 17, 2021

Published: August 20, 2021

Copyright $\odot 2021$ by author(s) and Scientific Research Publishing Inc. This work is licensed under the Creative Commons Attribution International License (CC BY 4.0).

http://creativecommons.org/licenses/by/4.0/

\begin{abstract}
This article discusses linguistic and pedagogical approaches in using games in Latin language lessons among first-year of Russian-speaking and Kyrgyz-speaking medical college students. The above approach activates students' cognitive activity in learning the Latin language, enriches their vocabulary in the learning process and thus is a means of intensifying the educational process.
\end{abstract}

\section{Keywords}

Medical Latin, Teaching through Games, Teaching Latin Language, Kyrgyz Speaking Students, Visualization, Tactile Method

\section{Introduction}

Study of terminology is one of the common elements in medical education in the Kyrgyz Republic, along with the post-Soviet countries. The main goals of teaching this discipline are to train a terminologically competent medical worker, develop the university quality, and the formation of future medical professionals' language culture. It should be noted, that in study of Latin language a practical focus is very important. Medical Latin language continued to be ordinary Latin with the admixture of numerous Greek and Latin medical terms (Wulff, 2004). Medical students and practitioners learn and use a vocabulary originating almost entirely from classical Latin and Greek languages (Smith et al., 2007). Teaching the Latin language in English is a challenge for students who it is not native; when learning Latin, special attention is paid to memorizing terms (Slugina, 2017). In the section "Clinical terminology" students should be introduced to the main Gre- 
co-Latin origin terminal elements (TEs) with the peculiarity of clinical terms formation and emphasis made to the general nature of terminology (Mereshchak, 2003).

In the process of studying the general professional ("Human Anatomy", "Pharmacology", "Histology") disciplines, students faced with medical terms, with the assimilation associated with knowledge of the Latin language. For example, without knowing the Latin language, it is very difficult to agree with all the words of anatomical terms, such as fascia diaphragmatis pelvis inferior (Chernyavsky et al., 1989: p. 109), or correctly understand and use medical clinical terms such as cephalgia, cystectomy, sialoadenitis, etc.

Latin is the basis of professional terminological and conceptual language for future doctors, necessary base and skills for mastering huge and multidisciplinary medical courses (Dolgushina, 2012: p. 3). Structural and thematic typologies of Latin terms and expressions were conducted with quantitative analysis that enabled to observe tendencies in using these lexical units in teaching medicine (Lysanets \& Bieliaieva, 2018). When teaching the Latin language and the basics of medical terminology in higher medical educational institutions, training, programmed, computer learning, discussion, case method, business and roleplaying game methods are widely used (Abdurakhmanova, 2019).

Rationality and relevance in this work were based on increasing Kyrgyz speaking students' number requiring study of lexico-semantic ways in medical terms formation through logical tasks and exercises in learning medical Latin language.

In this work, the lexico-semantic features were studied in the medical terms formation by reciprocal and terminology methods.

\section{Research Methods and Materials}

In teaching Latin language, we use games as a teaching method and effective tool for managing students learning activities. In this work, we are describing game strategy methods in teaching the Latin language to medical students within Kyrgyz speaking groups.

In this work, communication or conversation in the target language and the classroom work were achieved using the speech games. For the effectiveness of perception and not getting tired in Latin language course, students were offered this option. Working with Kyrgyz-speaking students is different from working with Russian-speaking students; Use of games in the learning process improves students' level and makes the learning process more effective.

\section{Results and Discussions}

Unlike games in general, a pedagogical game is a type of activity that characterizes a pedagogical result, as well as an educational and cognitive activity. The game aims to show interest in knowledge, science and learning. During game, students' objective and social content of activity recreated, systems of relationships, adequate conditions for the formation of a personality can be established. 
This type of pedagogical technique is interesting in creating an emotional uplift, makes the learning process exciting and creates cheerful working mood for students by facilitative learning. The game rationally complements traditional forms and methods of teaching, allow more effectively achieve the goals and objectives of specific activities in entire educational process. It is most effective method in the development of students thinking skills.

The game increases students' interest stimulates growth of cognitive activity, which allows receiving large amount of information. The game is informative; it includes problem situations, tasks, elements of brainstorming, as well as active physical action. The game allows you to relieve psychological fatigue, it can be used to mobilize the mental efforts of students, develop their organizational skills, develop self-discipline skills and create a situation of success among peers.

When choosing to work with students, the teacher firstly checks students' level of preparedness, the level of information perception, as well as the language of instruction at school. In our case, it can be a Russian, Kyrgyz school, or an Uzbek audience. Since the Latin language is mandatory for the first-year students' curriculum, for availability of information, the language of presentation is considered in advance.

\subsection{Game "Collect Aphorisms"}

The game aims to memorize proverbs, sayings in Latin and to gain understanding in Russian and native language because the contingent of students is not Russian-speaking. Also, to comprehend or find an equivalent in the native language, students were divided into three teams. Each group receives three cut-up phrases in Latin language. The task is to collect three different sentences from word segments. After that students should write equivalent meanings in Russian, Kyrgyz, Uzbek languages to explain the essence of sentence.

\subsection{Game "Don't Get Confused"}

The goal is to memorize words from the lexical minimum. Equipment: word list with transposed letters, pencils and paper, projector and whiteboard. Students presented with a list of confusing words on a blackboard, projector, or paper. It is proposed to guess the word. Then reconcile the noun with the adjective if it is an anatomical section, for example, ala (wing) dexter, tra, trum (right) "ala dextra" is right wing. And with the words of the clinical section, find the correct term, for example, chiro (hand) and mantia (fortune telling), which means "fortune telling by hand". The first one to master all the words wins gets a point. The length of the list depends on time allotted for the game. The words should be familiar to students. The list can be limited by the category of words meaning, for example, only anatomical or clinical terms, names of medicinal plants, drugs, diseases. With the help of this game, students can memorize not only word-terms, but also check grammar skills. 


\subsection{Game "Miracles Field"}

Having the number of letters, the student will try to correctly omit letters and endings, correctly substitute the word in desired gender, number and case in Latin language (Figure 1).

\subsection{Game "Collect the Recipe"}

The essence of this game based on students' ability to collect grammatically true recipe. Words, endings, punctuation marks from the recipe line are scattered on the board. Correct spelling of terms is very important because the recipe is an official document and no mistakes allowed. Letters, words marked conditionally red are not given to students; they need to add these gaps themselves (Figure 2). Students need to write the endings correctly, because they are hidden, as well as required expressions, verbs required in the recipe line. For example, "Signa" is a mandatory verb, after which a prescription is written to the patient in Russian. "Recipe:" or "Get", without which it is impossible to start the Latin part of the recipe. In this way, students train their memory in writing a recipe.

Memorizing foreign language terms is a laborious task. In this regard, in the learning process, it is advisable to use new forms and methods that contribute to the intensive assimilation of the material in the process of actively solving various educational problems. The statement of such problems in the form of cognitive questions, as well as tasks with elements of search activity encourages students to independently find the answer to the posed educational problems.

\section{5. "Find Terms with a Given Meaning"}

Clippings of terms that need to be found and agreed or inconsistent expressions are posted (Figure 3 ). When collecting anatomical expressions and translating

mucous glands of the bile ducts

\begin{tabular}{|c|c|c|c|c|c|c|c|c|c|c|c|c|}
\hline $\mathrm{g}$ & I & $a$ & $\mathrm{n}$ & $\mathrm{d}$ & $\mathrm{u}$ & $I$ & a & e & & & & \\
\hline $\mathrm{m}$ & $\mathrm{u}$ & C & 0 & s & a & e & & & & & & \\
\hline $\mathrm{d}$ & $\mathrm{u}$ & C & $t$ & $\mathrm{u}$ & $\mathrm{u}$ & $\mathrm{m}$ & & & & & & \\
\hline C & $h$ & 0 & I & $\mathrm{e}$ & $d$ & 0 & C & $\mathrm{h}$ & 0 & $r$ & $\mathrm{u}$ & $\mathrm{m}$ \\
\hline
\end{tabular}

stony nerve grooves

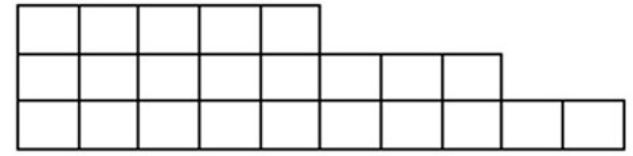

lattice hole walls

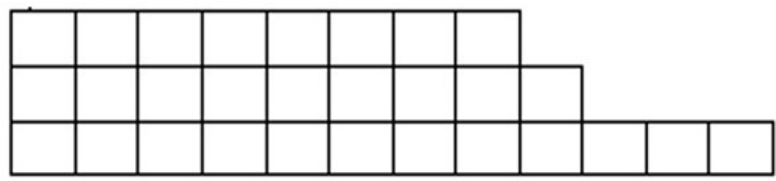

Figure 1. Questions for "Miracles Field" game in the Latin language. 


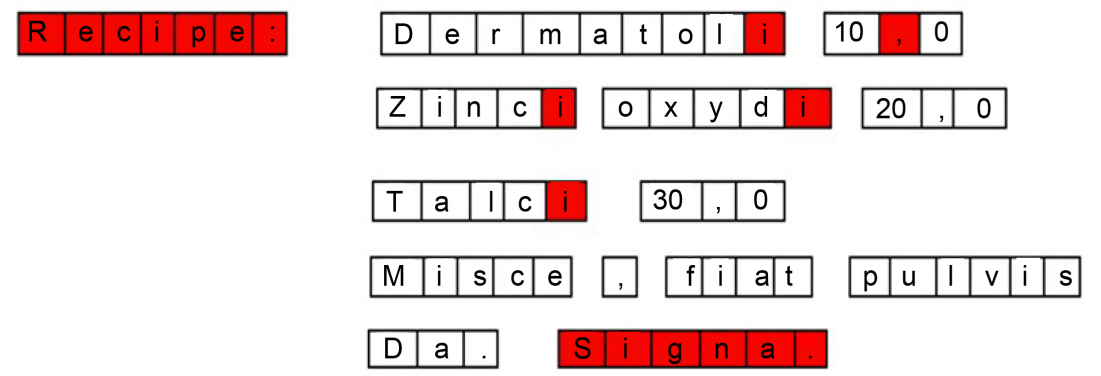

Figure 2. Example of phrases in game "Collect the recipe".

\begin{tabular}{|l|l|l|l|}
\hline perpendicular & bones & lamina & palatine \\
\hline vertebra & process & lumbar & articular \\
\hline circular & infraspinatus & bursa & muscle \\
\hline vertebralis & columna & incisura & vertebralis \\
\hline
\end{tabular}

Figure 3. Phrases in game "compose terms with a given meaning".

them into Latin language, Kyrgyz-speaking students need to convey the words order essence and change of endings in cases, as well as the presence of gender in nouns and adjectives. When studying the topic "Terminological word formation" by using terminal elements (TE). Clinical Terminology "game elements are offered for students in such tasks and exercises.

\subsection{Game "Logics"}

Only pictures displayed on the board, using pictures, according to the logic, it is necessary to find a terminal elements and create a whole term. The search for logical connections in pictures develops thinking process in students, improves pronunciation of terms and memorization of their spelling.

\subsection{Game "Logical Guess"}

It is also possible, instead of the Russian equivalents of the term, to visualize pictures with organs/body parts in teaching Kyrgyz-speaking or foreign students as shown in Figure 4.

\section{Describe the Following Science Sections, Having Previously Written the Latin Equivalent, Phrased into TEs}

1) Biology; 2) Osteology; 3) Pulmonology; 4) Gastroenterology; 5) Gynecology;

6) Andrology. The analysis of these science branches can be accordingly conducted in the students' native language. An equivalent can be given by students, but the practice of using these terms should be in the Latin language.

\section{Write the Latin Equivalent and Explain the Meaning of TEs}

1) Otitis media; 2) Dermatitis; 3) Helmentosis; 4) Osteoma; 5) Physiotherapy. 


\begin{tabular}{|l|l|l|l|}
\hline Russian word & Latin term & Greek TE & $\begin{array}{l}\text { Inflammation } \\
\text { type }\end{array}$ \\
\hline $\begin{array}{l}\text { Oral cavity } \\
\text { Örко }\end{array}$ & Os, oris n & Stomato- & Stomatitis \\
\hline Stomach & & & \\
\hline Ear & $?$ & & $?$ \\
\hline Student guess & $?$ & $?$ & $?$ \\
\hline
\end{tabular}

Figure 4. Example of words used in game "logical guess" in learning the Latin language.

\section{Brainstorming}

With the help of facial expressions, body parts, the student shows to other students the name of diseases, deviations, processes, science, etc., terms for problem solving, and so on. It is easier for students to memorize visualized objects or actions. Tactile touching of their organs and body parts helps students to intensify the terms memorization.

The use of such games in the Latin language classes teach students to consciously and correctly use the Latin medical terms, as well as the ability to work with Russian, Kyrgyz medical terms, find, compare their equivalents in native language, and apply in the future professional activities. Lexical material learned by students based on associative connections, tactile methods, and visual techniques.

The main indicator in the development of perfected skills and abilities in the process of mastering and solving logical problems and games is the ability to work in a team, building a chain of thoughts and its development when passing the levels of multitasking. The use of games and logical tasks train memory, stimulates and motivates students with activity to study the material, and leads to self-discipline of students. The educational effect of games can be explained from different pedagogical perspectives: behaviorist, cognitive, humanist, and constructivist (Gorbanev et al., 2018).

\section{Conclusion}

The use of gaming technologies and elements of problem-based learning stimulates personal activity of students, develops cognitive thinking and contributes to formation of competencies that a medical student should have:

- Ability and willingness to use knowledge of medical terminology (anatomical, clinical, pharmaceutical) in professional activities;

- Ability to use in practice the terminology of natural, biomedical and clinical 
sciences in various activities;

- Willingness to formulate a systematic approach in analysis of medical information from various sources;

- Willingness to work independently and individually, to make responsible decisions within the framework of their professional competence;

- Ability to work with equivalents in the native language and develop professional vocabulary in the Latin language;

- Ability to logically approach tasks, develop critical thinking.

Practical suggestions for medical students to develop necessary abilities in Latin language course can be achieved by perception of terms through games and equivalents in the native language.

\section{Conflicts of Interest}

The authors declare no conflicts of interest regarding the publication of this paper.

\section{References}

Abdurakhmanova, M. U. (2019). Methods of Interactive Teaching of the Latin Language in Higher Medical Educational Institutions. Bulletin of Science and Education, 13-2, No. 67, 35-37.

Chernyavsky, M. N., Tverkovkina, E. P., Okatova, L. M., Ermicheva, V. I., Zalenskaya, R. M., Vasilyeva, L. I., \& Semenyuk, L. P. (1989). Latin and the Basics of Medical Terminology (2nd ed.). Higher School, 352 p.

Dolgushina, L. V. (2012). Educational Methodological Complex for Discipline "Latin Language and the Basics of Medical Terminology". Novosibirsk: Faculty of Novosibirsk State University, $118 \mathrm{p}$.

Gorbanev, I., Agudelo-Londoño, S., González, R. A., Cortes, A., Pomares, A., Delgadillo, V., Yepes, F. J., \& Muñoz, Ó. (2018). A Systematic Review of Serious Games in Medical Education: Quality of Evidence and Pedagogical Strategy. Medical Education Online, 23, Article ID: 1438718. https://doi.org/10.1080/10872981.2018.1438718

Lysanets, Y. V., \& Bieliaieva, O. M. (2018). The Use of Latin Terminology in Medical Case Reports: Quantitative, Structural, and Thematic Analysis. Journal of Medical Case Reports, 12, Article No. 45. https://doi.org/10.1186/s13256-018-1562-x

Mereshchak, N. G. (2003). Features of Teaching Medical Latin to Foreign Students. Bulletin of Vitebsk State Medical University, 2, 102-103.

Slugina, O. V. (2017). Features of Teaching Latin to Medical Students Studying in English. Philological Sciences. Questions of Theory and Practice, 6-1, No. 72, 208-210.

Smith, S. B., Carmichael, S. W., Pawlina, W., \& Spinner, R. J. (2007). Latin and Greek in Gross Anatomy. Clinical Anatomy, 20, 332-337. https://doi.org/10.1002/ca.20342

Wulff, H. R. (2004). The Language of Medicine. Journal of the Royal Society of Medicine, 97, 187-188. https://doi.org/10.1177/014107680409700412 